\title{
Maternal seafood consumption and infant birth weight, length and head circumference in the Norwegian Mother and Child Cohort Study
}

\author{
Anne Lise Brantsæter ${ }^{1 *}$, Bryndis Eva Birgisdottir ${ }^{1}$, Helle Margrete Meltzer ${ }^{1}$, Helen Engelstad Kvalem ${ }^{1}$, \\ Jan Alexander ${ }^{1}$, Per Magnus ${ }^{2}$ and Margareta Haugen ${ }^{1}$ \\ ${ }^{1}$ Division of Environmental Medicine, Norwegian Institute of Public Health, PO Box 4404, Nydalen, NO-0403 Oslo, Norway \\ ${ }^{2}$ Division of Epidemiology, Norwegian Institute of Public Health, PO Box 4404, Nydalen, NO-0403 Oslo, Norway
}

(Received 15 November 2010 - Revised 4 May 2011 - Accepted 4 May 2011 - First published online 18 July 2011)

\begin{abstract}
Results from previous studies on associations between maternal fish and seafood intakes and fetal growth are inconclusive. The aim of the present study was to investigate how maternal intakes of seafood, subtypes of seafood and supplementary $n$ - 3 fatty acids were associated with infant birth weight, length and head circumference in a prospective study in Norway. The study population included 62099 participants in the Norwegian Mother and Child Cohort Study. The mothers answered an FFQ in mid pregnancy. The FFQ comprised detailed questions about intake of various seafood items and $n-3$ supplements. Data on infant birth weight, length and head circumference were obtained from the Medical Birth Registry. We used multivariable regression to examine how total seafood, various seafood subtypes and supplementary $n$-3 intakes were associated with birth size measures. Total seafood intake was positively associated with birth weight and head circumference. Lean fish was positively associated with all birth size measures; shellfish was positively associated with birth weight, while fatty fish was not associated with any birth size measures. Intake of supplementary $n-3$ was negatively associated with head circumference. The relative risk of giving birth to a small baby $(<2500 \mathrm{~g})$ in full-term pregnancies was significantly lower in women who consumed $>60 \mathrm{~g} / \mathrm{d}$ of seafood than in women who consumed $\leq 5 \mathrm{~g} / \mathrm{d}$ (OR $=0.56$ (95\% CI $0 \cdot 35,0 \cdot 88)$. In conclusion, maternal seafood consumption was positively associated with birth size, driven by lean fish intake, while supplementary $n$ - 3 intake was negatively associated with infant head circumference.
\end{abstract}

Key words: Maternal seafood consumption: Birth weight: Birth length: Head circumference: FFQ

Birth weight is considered a marker of intrauterine development. It is a strong predictor of infant survival and an indicator of health status later in life ${ }^{(1-3)}$. Maternal diet and nutritional status during pregnancy is an important determinant of fetal growth $^{(4)}$. Seafood is not only a rich source of nutrients such as marine $n-3$ fatty acids, vitamin $\mathrm{D}$, iodine and $\mathrm{Se}$, but can also be a source of pollutants such as methylmercury, As and polychlorinated biphenyls ${ }^{(5,6)}$. Several observational studies have reported a positive association between maternal seafood consumption and fetal growth ${ }^{(7-11)}$. Some observational studies also associate marine $n$ - 3 fatty acid intake with greater growth measures at birth ${ }^{(12,13)}$. However, other observational studies have reported negative associations between maternal seafood and $n-3$ intake and fetal growth. In the Danish national birth cohort, intake of fatty fish, but not lean fish, was negatively associated with fetal growth ${ }^{(14)}$, while other studies have reported negative associations between marine $n$-3 fatty acids from fish ${ }^{(15,16)}$ or fish-oil supplements ${ }^{(10)}$ and fetal growth measures. These results might be compatible with a hypothesis that there is a differential influence by different types and/or constituents of fish and seafood on fetal growth and birth size $\mathrm{e}^{(17-19)}$. The negative association with birth measures has frequently been attributed to the presence of hazardous pollutants, as fatty fish and marine $n$-3 supplements are likely to contain more persistent organic pollutants than lean fish ${ }^{(10,14,20)}$. The concentrations of pollutants not only vary among different fish and seafood species, but also depend strongly on habitat, life stage and origin $^{(21,22)}$. Further studies of associations between maternal intake of subtypes of seafood and supplementary marine $n-3$ fatty acids and infant birth measures are warranted.

Norwegians traditionally have relatively high fish and seafood consumption, especially in the coastal areas, but national surveys have shown decreasing intakes over the past dec$\operatorname{ades}^{(23)}$. In general, young women have the lowest fish consumption. We have previously reported a wide range of fish and seafood intakes among pregnant Norwegian women $^{(24,25)}$. An additional source of marine $n-3$ fatty acids

Abbreviations: MBRN, Medical Birth Registry of Norway; MoBa, the Norwegian Mother and Child Cohort Study.

*Corresponding author: A. L. Brantsæeter, fax +47 21 076243, email anne.lise.brantsaeter@fhi.no 
is cod-liver oil or fish-oil supplements, which are the most frequently used dietary supplements in pregnant Norwegian women $^{(26)}$.

The aim of the present study was to address the hypothesis that different seafood subtypes differentially influence pregnancy outcomes by examining how maternal seafood consumption, including intake of lean and fatty fish, shellfish and fish liver, and supplementary marine $n$ - 3 fatty acids, was associated with infant birth weight, birth length and head circumference in a large cohort of pregnant Norwegian women.

\section{Materials and methods \\ Population and study design}

The data set is part of the Norwegian Mother and Child Cohort Study (MoBa), initiated by and maintained at the Norwegian Institute of Public Health ${ }^{(27)}$. The present study was conducted according to the guidelines laid down in the Declaration of Helsinki and all procedures involving human subjects were approved by the Regional Committee for Ethics in Medical Research and the Norwegian Data Inspectorate. Written informed consent was obtained from all MoBa participants.

In brief, MoBa is a nation-wide pregnancy cohort that has included more than 107000 pregnancies in the years from 1999 to 2009. Women were recruited to the study through a postal invitation in connection with a routine ultrasound examination offered to all pregnant women in Norway. The participation rate in $\mathrm{MoBa}$ was $43 \%^{(27)}$. The potential bias due to self-selection in MoBa has been evaluated. Despite differences in prevalence estimates between the cohort participants and the total population of pregnant women, no statistically relative differences in association measures were found regarding eight exposure-outcome associations evaluated, e.g. prenatal smoking and low birth weight $(<2500 \mathrm{~g})$, maternal vitamin use and placental abruption, and parity and pre-eclampsia ${ }^{(28)}$.

The present study uses the quality-assured data files released for research in 2009 (version 4). Pregnancy and birth records from the Medical Birth Registry of Norway (MBRN) are linked to the MoBa database ${ }^{(29)}$. When preparing the data set, 76218 women had answered the MoBa FFQ (Q2), the baseline MoBa questionnaire covering sociodemographic information and general health (Q1) and the data were recorded in MBRN. We included only the first participation for women with multiple participation in MoBa and women with singleton births. This led to the exclusion of 12240 women. Furthermore, we excluded participants with a pregnancy duration $<28$ weeks or $>42$ weeks ( $n$ 628), if the birth weight of the baby had not been recorded or if the birth weight was $<600 \mathrm{~g}$ ( $n$ 35). We also excluded participants who had not given birth to a live baby ( $n$ 153). Lastly, we excluded women having improbable energy intakes, i.e. energy intake $<4.5 \mathrm{MJ}$ or $>20 \mathrm{MJ}$ ( $n$ 1063), resulting in a final sample of 62099 women for the present study (Fig. 1). Maternal weight gain in pregnancy was available for a subset of participants who, at the time when the present

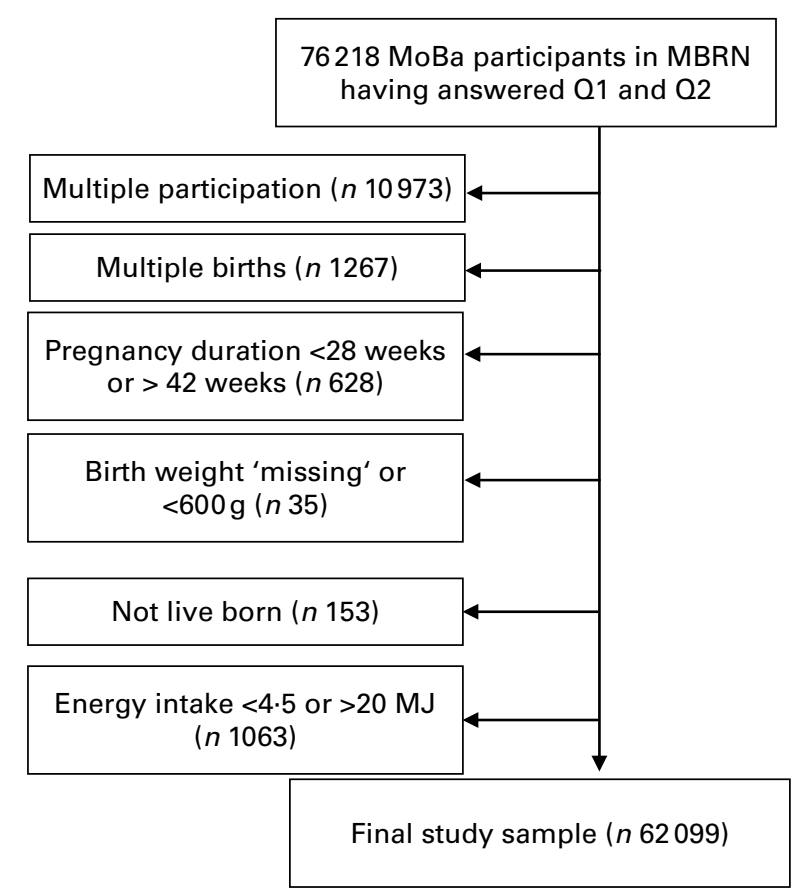

Fig. 1. Sample selection for the present study for inclusion of participants for studying fetal growth in Norwegian Mother and Child Cohort Study (MoBa). MBRN, Medical Birth Registry of Norway; Q1, baseline MoBa questionnaire covering sociodemographic information and general health; Q2, MoBa FFQ.

data files were released, also had answered a questionnaire at 6 months post-partum ( $n$ 42907).

\section{Dietary assessment}

The MoBa FFQ (available at http://www.fhi.no/dokumenter/ 011fbd699d.pdf) was completed around the 22nd week of gestation and the dietary data were collected from February 2002 and onwards ${ }^{(24)}$. The MoBa FFQ is a semi-quantitative questionnaire designed to capture dietary habits and intake of dietary supplements during the first 4-5 months of pregnancy. The FFQ included questions about intake of 255 food items with special emphasis on various seafood items. There are ten questions about cold cuts and spreads made from fish or shellfish, sixteen questions about fish or shellfish eaten for dinner and four questions about cod-liver oil, cod-liver oil capsules or fish-oil capsules.

Nutrient calculations were performed with the use of FoodCalc $^{(30)}$ and the Norwegian food composition table $\mathrm{e}^{(31)}$ The FFQ has been thoroughly validated with regard to nutrients, foods and dietary supplement use $\mathrm{e}^{(32,33)}$.

\section{Definition of fish and seafood variables and $\mathrm{n}-3$ supplement intake}

The daily intakes $(\mathrm{g} / \mathrm{d})$ of fish and seafood items were grouped into four categories. The first category comprised all items of lean fish eaten as bread spread, dinner fillets or in a mixed item such as fish fingers or fish au gratin. This category included cod, saithe, haddock, pollock, halibut, plaice, flounder, tuna, perch, pike, cat-fish and fish roe $(0 \cdot 3-6 \cdot 0 \%$ 
fat). The second category comprised the fatty fish items of mackerel, herring, salmon and trout (10-24\% fat). The third category was cod liver (about 60\% fat) either as dinner or as bread spread (liver and roe pâté). The fourth category comprised shellfish and included shrimp, crab and mussels $(0 \cdot 8-2 \cdot 5 \%$ fat $)$. Cod liver was kept as a separate category because of its relatively high concentration of persistent organic pollutants such as polychlorinated biphenyls, dioxins, various organochlorine pesticides and polybrominated diphenylethers $^{(22,34,35)}$. Total seafood was the combined intake of all fish and seafood items.

When evaluating the association between seafood consumption and fetal growth, seafood intake was treated as a continuous variable $(\mathrm{g} / \mathrm{d})$ and divided into the following categories: $0-5,>5-20,>20-40,>40-60$ and $>60 \mathrm{~g} / \mathrm{d}$. These categories correspond to the categories used in a recent study from the Danish National Birth Cohort ${ }^{(14)}$. Assuming a serving size of $140 \mathrm{~g}$, these categories correspond to; rarely, $<1$ serving/week, 1-2 servings/week, 2-3 servings/week and 3 or more servings/week. When seafood was eaten as bread spread the serving size was estimated as $20-25 \mathrm{~g}$.

The intake $(\mathrm{mg} / \mathrm{d})$ of marine $n-3$ fatty acids from supplements (cod-liver oil, cod-liver oil capsules and fish-oil capsules) was estimated from the FFQ. Supplementary $n-3$ was examined as a continuous variable and divided into three categories, with non-users as one group and consumers ranked into two groups by their estimated total intake of EPA, docosapentaenoic acid and DHA from supplements.

\section{Outcome variables}

Birth weight, birth length and head circumference were measured by the midwife who attended the birth and reported these to the $\mathrm{MBRN}^{(29)}$. Data from MBRN also included information on pregnancy duration. Only observations of birth length and head circumference falling within a realistic range were used $(35-65 \mathrm{~cm}$ for birth length and $25-45 \mathrm{~cm}$ for head circumference), resulting in $n 59595$ (96\%) for the analysis of birth length and $n 60805$ (98\%) for the analysis of head circumference. Infant birth weight was also examined as dichotomous outcomes, first as birth weight $<2500 \mathrm{~g}$ and second as birth weight $>4500 \mathrm{~g}$. These outcomes were only examined in term pregnancies ( $\geq 37$ weeks), resulting in $n 59058$ (95\%). Both of these outcomes have been associated with maternal and/or perinatal complications ${ }^{(36,37)}$.

\section{Other variables}

We included variables previously shown to be associated with fetal growth, which were also associated with the consumption of fish and seafood. Maternal age at delivery was used as a continuous variable except in Table 1 where is was divided into four categories $(<25,25-29,30-34$ and $35+$ years). BMI was calculated from self-reported height and weight before the pregnancy and categorized according to the WHO classification as normal $\left(18.5-24.9 \mathrm{~kg} / \mathrm{m}^{2}\right)$, underweight $\left(\leq 18.5 \mathrm{~kg} / \mathrm{m}^{2}\right)$, overweight $\left(25 \cdot 0-29 \cdot 9 \mathrm{~kg} / \mathrm{m}^{2}\right)$ and obese $\left(\geq 30.0 \mathrm{~kg} / \mathrm{m}^{2}\right)$. Height was divided into quartiles. Parity was based on data from both MoBa and MBRN and categorized into number of previous pregnancies of $>22$ weeks' duration. Pregnancy duration (MBRN information) was based on ultrasound and used as a continuous variable except in Table 1. Other variables included were total energy intake (continuous), maternal educational attainment ( $\leq 12,13-16$ and $17+$ years), first trimester smoking habits (non-smoker, occasional smoker or daily smoker) and whether the respondent or her partner did not have Norwegian as their mother tongue. Participants with unknown/missing values for BMI, height, education or smoking were grouped in a 'missing data' category.

\section{Statistical methods}

We used linear regression to calculate $P$ for trend when examining seafood intake across the ordered categories and Student's $t$ test for dichotomous variables. Associations between seafood consumption and birth weight, birth length and head circumference were analysed using multiple linear regression. For the dichotomous outcomes, we calculated relative risks as $\mathrm{OR}$ and controlled for confounding with multiple logistic regression.

All regression models were adjusted for potential confounding by maternal age, height, BMI, parity, education, smoking in pregnancy, pregnancy duration, mother tongue other than Norwegian, total energy intake and marine $n-3$ intake. The variance inflation factor test for multicollinearity was well within limits, indicating that all confounders in the model could reliably assess their independent contribution.

We examined potential interactions between seafood consumption and other food intakes. No significant interactions were seen. All models were checked for violations from the model assumptions.

All analyses were performed using the statistical software PASW statistics 17 (SPSS, Inc., Chicago, IL, USA) and $P<0.05$ was considered significant.

\section{Results}

Consumption of fish or seafood was reported by $98 \%$ of the women in this study, with $6 \%$ reporting no consumption of lean fish, $11 \%$ reporting no consumption of fatty fish, $35 \%$ no consumption of shellfish and $94 \%$ no consumption of fish liver. Use of $n$-3-containing supplements was reported by $66.5 \%$ of the women.

The average intake was $36 \mathrm{~g} / \mathrm{d}$ (median 33) of total seafood, $20 \mathrm{~g} / \mathrm{d}$ (median 19) of lean fish, $12 \mathrm{~g} / \mathrm{d}$ (median 8 ) of fatty fish, $4 \mathrm{~g} / \mathrm{d}$ (median 2) of shellfish and $<0 \cdot 1 \mathrm{~g} / \mathrm{d}$ of fish liver. Lean fish constituted $58 \%$, fatty fish $31 \%$ and shellfish $11 \%$ of total seafood consumption.

Seafood contributed on average to $2 \cdot 9 \%$ of the total energy intake, $7 \cdot 2 \%$ of the total protein intake and $4 \cdot 8 \%$ of the total fat intake. For comparison, the average intake of meat was $83 \mathrm{~g} / \mathrm{d}$ and meat contributed $7 \cdot 0 \%$ of total energy, $17 \cdot 8 \%$ of total protein and $12 \cdot 2 \%$ of total fat intake.

The consumption of seafood, specified as lean or fatty fish, differed across categories of participant characteristics (Table 1). The consumption of seafood increased with 
increasing maternal age, height, parity, length of education, energy intake and $n-3$ supplement use. The intakes of lean and fatty fish were higher among women in the normal BMI category than among under- or overweight women, and higher among non-smokers than smokers. Women with mother tongue other than Norwegian, or a partner in this category, had lower intake of seafood, but this only pertained to lean fish (Table 1).

Table 1. Seafood intake according to maternal characteristics among 62099 women in the Norwegian Mother and Child Cohort Study, $2002-2008$ (Medians and percentiles)

\begin{tabular}{|c|c|c|c|c|c|c|c|c|c|c|c|}
\hline & \multirow[b]{2}{*}{$n$} & \multirow[b]{2}{*}{$\%$} & \multicolumn{3}{|c|}{ Total seafood* (g/d) } & \multicolumn{3}{|c|}{ Lean fish $(\mathrm{g} / \mathrm{d})$} & \multicolumn{3}{|c|}{ Fatty fish $(\mathrm{g} / \mathrm{d})$} \\
\hline & & & Median & P5th & P95th & Median & P5th & P95th & Median & P5th & P95th \\
\hline \multicolumn{12}{|l|}{ Maternal age at delivery } \\
\hline$<25$ years & 7333 & $11 \cdot 8$ & $29 \cdot 4$ & 0.5 & $75 \cdot 0$ & $16 \cdot 7$ & 0 & $47 \cdot 7$ & $6 \cdot 3$ & 0 & $37 \cdot 5$ \\
\hline $25-29$ years & 21170 & $34 \cdot 1$ & $31 \cdot 8$ & $5 \cdot 1$ & $74 \cdot 3$ & $17 \cdot 6$ & 0 & $44 \cdot 8$ & $7 \cdot 7$ & 0 & $36 \cdot 9$ \\
\hline $30-34$ years & 26171 & $42 \cdot 1$ & $31 \cdot 8$ & $5 \cdot 1$ & $74 \cdot 3$ & $19 \cdot 3$ & $1 \cdot 4$ & $45 \cdot 7$ & $8 \cdot 4$ & 0 & $38 \cdot 5$ \\
\hline$\geq 35$ years & 7425 & $12 \cdot 0$ & $31 \cdot 8$ & $5 \cdot 1$ & $74 \cdot 3$ & $21 \cdot 8$ & 2.9 & $48 \cdot 2$ & $9 \cdot 7$ & 0 & $41 \cdot 4$ \\
\hline$P \dagger$ & & & & $<0.001$ & & & $<0.001$ & & & $<0.001$ & \\
\hline \multicolumn{12}{|l|}{ Maternal height } \\
\hline $140-164 \mathrm{~cm}$ & 16755 & $27 \cdot 0$ & $33 \cdot 0$ & $4 \cdot 4$ & $76 \cdot 8$ & $18 \cdot 6$ & 0 & $46 \cdot 8$ & $7 \cdot 7$ & 0 & $38 \cdot 3$ \\
\hline $165-168 \mathrm{~cm}$ & 15686 & $25 \cdot 3$ & 33.4 & $6 \cdot 3$ & $76 \cdot 8$ & $18 \cdot 8$ & 0 & 45.9 & $8 \cdot 1$ & 0 & $37 \cdot 6$ \\
\hline $169-172 \mathrm{~cm}$ & 14774 & $23 \cdot 8$ & 33.7 & $6 \cdot 6$ & $76 \cdot 1$ & $18 \cdot 9$ & 0 & $45 \cdot 7$ & $8 \cdot 3$ & 0 & $38 \cdot 1$ \\
\hline $173+\mathrm{cm}$ & 14172 & $22 \cdot 8$ & 33.6 & $6 \cdot 6$ & $76 \cdot 0$ & $18 \cdot 8$ & 0 & $45 \cdot 0$ & 8.4 & 0 & 38.9 \\
\hline$P \dagger$ & & & & 0.008 & & & 0.662 & & & $<0.001$ & \\
\hline Missing data & 712 & $1 \cdot 1$ & $34 \cdot 1$ & 2.9 & $80 \cdot 1$ & $18 \cdot 5$ & 0 & $46 \cdot 6$ & $7 \cdot 6$ & 0 & $44 \cdot 6$ \\
\hline \multicolumn{12}{|l|}{ Pre-pregnancy BMI $\left(\mathrm{kg} / \mathrm{m}^{2}\right)$} \\
\hline$<18.5$ & 1809 & 2.9 & $33 \cdot 2$ & $5 \cdot 1$ & $80 \cdot 6$ & $18 \cdot 7$ & 0 & $46 \cdot 4$ & $7 \cdot 8$ & 0 & $40 \cdot 7$ \\
\hline $18 \cdot 5-24 \cdot 9$ & 39653 & 63.9 & $33 \cdot 8$ & $6 \cdot 6$ & $76 \cdot 3$ & $19 \cdot 0$ & 0 & $45 \cdot 7$ & $8 \cdot 3$ & 0 & $38 \cdot 1$ \\
\hline $25-29 \cdot 9$ & 13204 & $21 \cdot 3$ & 32.5 & $5 \cdot 3$ & 74.7 & $18 \cdot 4$ & 0 & $45 \cdot 6$ & $7 \cdot 8$ & 0 & $37 \cdot 4$ \\
\hline$\geq 30$ & 5777 & $9 \cdot 3$ & $32 \cdot 5$ & $5 \cdot 3$ & 74.7 & $17 \cdot 7$ & 0 & $47 \cdot 1$ & $7 \cdot 6$ & 0 & 39.5 \\
\hline$P \dagger$ & & & & $<0.001$ & & & $<0.001$ & & & $<0.001$ & \\
\hline Missing data & 656 & $2 \cdot 7$ & 33.9 & $3 \cdot 3$ & $81 \cdot 3$ & $18 \cdot 8$ & 0 & $48 \cdot 0$ & $7 \cdot 4$ & 0 & 43.4 \\
\hline \multicolumn{12}{|l|}{ Parity } \\
\hline Nulliparous & 33061 & $53 \cdot 2$ & $31 \cdot 6$ & $4 \cdot 6$ & 74.4 & $17 \cdot 1$ & 0 & $44 \cdot 3$ & $8 \cdot 0$ & 0 & $37 \cdot 4$ \\
\hline Multiparous & 29038 & $46 \cdot 8$ & $35 \cdot 4$ & $7 \cdot 8$ & $78 \cdot 9$ & $20 \cdot 7$ & 1.0 & $47 \cdot 6$ & $8 \cdot 2$ & 0 & $39 \cdot 2$ \\
\hline$P \dagger$ & & & & $<0.001$ & & & $<0.001$ & & & 0.004 & \\
\hline Missing data & 59 & 0.1 & $35 \cdot 0$ & $10 \cdot 7$ & $65 \cdot 6$ & $17 \cdot 2$ & $3 \cdot 1$ & $39 \cdot 1$ & $10 \cdot 9$ & 0 & 39.5 \\
\hline \multicolumn{12}{|l|}{ Pregnancy duration } \\
\hline 28-36 weeks & 3041 & 4.9 & $32 \cdot 3$ & $3 \cdot 3$ & $79 \cdot 1$ & $17 \cdot 8$ & 0 & $45 \cdot 6$ & 7.5 & 0 & $41 \cdot 2$ \\
\hline $37-38$ weeks & 10169 & $16 \cdot 4$ & 33.5 & $5 \cdot 0$ & $77 \cdot 6$ & $18 \cdot 8$ & 0 & $46 \cdot 4$ & $8 \cdot 1$ & 0 & $38 \cdot 3$ \\
\hline $39-42$ weeks & 48889 & $78 \cdot 7$ & 33.5 & $6 \cdot 3$ & $76 \cdot 1$ & $18 \cdot 8$ & 0 & $45 \cdot 8$ & $8 \cdot 1$ & 0 & $38 \cdot 0$ \\
\hline$P \dagger$ & & & & $0 \cdot 102$ & & & 0.048 & & & 0.673 & \\
\hline \multicolumn{12}{|l|}{ Maternal education } \\
\hline$\leq 12$ years & 19984 & $32 \cdot 2$ & $31 \cdot 6$ & $3 \cdot 6$ & $76 \cdot 3$ & $18 \cdot 3$ & 0 & $49 \cdot 7$ & $7 \cdot 0$ & 0 & $39 \cdot 1$ \\
\hline $13-16$ years & 25833 & 41.6 & $33 \cdot 6$ & $7 \cdot 4$ & 74.0 & $18 \cdot 9$ & $1 \cdot 2$ & $44 \cdot 1$ & $8 \cdot 3$ & 0 & $37 \cdot 4$ \\
\hline$\geq 17$ years & 14916 & $24 \cdot 0$ & 34.6 & $9 \cdot 4$ & 75.9 & $19 \cdot 2$ & 2.5 & $44 \cdot 1$ & $9 \cdot 1$ & 0 & $37 \cdot 8$ \\
\hline$P \dagger$ & & & & $<0.001$ & & & 0.014 & & & $<0.001$ & \\
\hline Missing data & 1366 & $2 \cdot 2$ & $31 \cdot 3$ & 3.5 & $77 \cdot 2$ & $17 \cdot 2$ & 0 & $47 \cdot 3$ & $7 \cdot 2$ & 0 & $39 \cdot 1$ \\
\hline \multicolumn{12}{|l|}{ Smoking in pregnancy } \\
\hline Non-smoker & 56399 & $90 \cdot 8$ & 33.5 & $6 \cdot 5$ & $76 \cdot 1$ & $18 \cdot 8$ & 0 & $45 \cdot 5$ & $8 \cdot 2$ & 0 & $38 \cdot 3$ \\
\hline Occasional & 1769 & $2 \cdot 8$ & $32 \cdot 9$ & $2 \cdot 2$ & $79 \cdot 0$ & $18 \cdot 2$ & 0 & $50 \cdot 0$ & $7 \cdot 1$ & 0 & 35.9 \\
\hline Daily & 3480 & $5 \cdot 6$ & $32 \cdot 0$ & 0.6 & $80 \cdot 4$ & $18 \cdot 2$ & 0 & $50 \cdot 6$ & $6 \cdot 2$ & 0 & $38 \cdot 8$ \\
\hline$P \dagger$ & & & & 0.013 & & & 0.177 & & & $<0.001$ & \\
\hline Missing data & 451 & 0.7 & $34 \cdot 7$ & $2 \cdot 0$ & $84 \cdot 7$ & 18.9 & 0 & $46 \cdot 3$ & $8 \cdot 3$ & 0 & $36 \cdot 0$ \\
\hline \multicolumn{12}{|l|}{ Mother tongue } \\
\hline Norwegian & 58427 & $94 \cdot 1$ & $33 \cdot 6$ & $6 \cdot 3$ & $76 \cdot 3$ & $19 \cdot 0$ & 0 & $46 \cdot 0$ & $8 \cdot 1$ & 0 & $38 \cdot 1$ \\
\hline Other than Norwegian & 3672 & $5 \cdot 9$ & $29 \cdot 8$ & $2 \cdot 0$ & $81 \cdot 0$ & $15 \cdot 1$ & 0 & $43 \cdot 2$ & $8 \cdot 5$ & 0 & $40 \cdot 1$ \\
\hline$P \dagger$ & & & & $<0.001$ & & & $<0.001$ & & & 0.037 & \\
\hline \multicolumn{12}{|l|}{ Quartiles of energy intake } \\
\hline $4.5-7.9 \mathrm{MJ}$ & 15524 & $25 \cdot 0$ & $29 \cdot 4$ & 3.0 & $66 \cdot 2$ & $17 \cdot 0$ & 0 & $45 \cdot 3$ & $6 \cdot 6$ & 0 & $27 \cdot 9$ \\
\hline $7 \cdot 9-6.4 \mathrm{MJ}$ & 15525 & $25 \cdot 0$ & $32 \cdot 8$ & 6.5 & 70.9 & $18 \cdot 6$ & 0 & $44 \cdot 4$ & $7 \cdot 9$ & 0 & $34 \cdot 2$ \\
\hline $9 \cdot 4-11 \cdot 2 \mathrm{MJ}$ & 15525 & $25 \cdot 0$ & 34.6 & $7 \cdot 4$ & $75 \cdot 6$ & $19 \cdot 3$ & 1.0 & $45 \cdot 4$ & $8 \cdot 7$ & 0 & 38.9 \\
\hline $11 \cdot 2-19 \cdot 9 \mathrm{MJ}$ & 15525 & $25 \cdot 0$ & $37 \cdot 3$ & $7 \cdot 2$ & $90 \cdot 6$ & $20 \cdot 1$ & 0 & $48 \cdot 5$ & $9 \cdot 5$ & 0 & $50 \cdot 6$ \\
\hline$P \dagger$ & & & & $<0.001$ & & & $<0.001$ & & & $<0.001$ & \\
\hline Supplementary n-3 & & & & & & & & & & & \\
\hline 0 & 20820 & 33.5 & $32 \cdot 5$ & $3 \cdot 3$ & $75 \cdot 8$ & $18 \cdot 6$ & 0 & $47 \cdot 9$ & $7 \cdot 2$ & 0 & $37 \cdot 4$ \\
\hline$>0-0.39 \mathrm{~g} / \mathrm{d}$ & 20628 & $33 \cdot 2$ & $32 \cdot 2$ & $6 \cdot 8$ & $72 \cdot 8$ & $18 \cdot 1$ & 0.9 & $43 \cdot 2$ & $7 \cdot 9$ & 0 & $36 \cdot 0$ \\
\hline $0.40-6.9 \mathrm{~g} / \mathrm{d}$ & 20651 & $33 \cdot 3$ & 35.5 & $7 \cdot 7$ & $80 \cdot 0$ & $19 \cdot 7$ & 0.8 & $46 \cdot 5$ & $9 \cdot 1$ & $0.41 \cdot 0$ & \\
\hline$P \dagger$ & & & & $<0.001$ & & & $<0.001$ & & & $<0.001$ & \\
\hline
\end{tabular}

P5th, 5th percentile; P95th, 95th percentile.

* Total seafood comprises lean fish (including fish in products), fatty fish, fish liver and shellfish.

$\dagger P$ for trend or for differences between groups depending on whether categories are ordinal or nominal. 
Table 2. Daily intake of various fish and seafood categories by subtypes of total seafood intake among 62099 women in the Norwegian Mother and Child Cohort Study, 2002-2008

(Mean values and standard deviations)

\begin{tabular}{|c|c|c|c|c|c|c|c|c|c|c|c|c|}
\hline \multirow{2}{*}{$\begin{array}{l}\text { Total } \\
\text { seafood }(g / d)^{*}\end{array}$} & \multirow[b]{2}{*}{$n$} & \multirow[b]{2}{*}{$\%$} & \multicolumn{2}{|c|}{ Lean fish $(\mathrm{g} / \mathrm{d})$} & \multicolumn{2}{|c|}{ Fatty fish $(\mathrm{g} / \mathrm{d})$} & \multicolumn{2}{|c|}{ Fish liver $(\mathrm{g} / \mathrm{d})$} & \multicolumn{2}{|c|}{ Shellfish (g/d) } & \multicolumn{2}{|c|}{$\begin{array}{l}\text { Supplementary } \\
n-3(\mathrm{~g} / \mathrm{d})\end{array}$} \\
\hline & & & Mean & SD & Mean & SD & Mean & SD & Mean & SD & Mean & SD \\
\hline$\leq 5$ & 2808 & 4.5 & 0.5 & 1.1 & 0.5 & $1 \cdot 1$ & 0.00 & 0.0 & 0.3 & 0.8 & 0.47 & 0.87 \\
\hline$>5-20$ & 11410 & $18 \cdot 4$ & 8.2 & 4.5 & 4.0 & 3.5 & 0.01 & 0.1 & 1.9 & $2 \cdot 4$ & 0.49 & 0.81 \\
\hline$>20-40$ & 25013 & $40 \cdot 3$ & $18 \cdot 2$ & 7.4 & 8.4 & $6 \cdot 0$ & 0.04 & 0.3 & 3.4 & 3.7 & 0.57 & 0.86 \\
\hline$>40-60$ & 15100 & $24 \cdot 3$ & $28 \cdot 8$ & $10 \cdot 6$ & $15 \cdot 5$ & 9.9 & 0.08 & $0 \cdot 6$ & 4.5 & $5 \cdot 2$ & 0.63 & 0.91 \\
\hline$>60$ & 7768 & 12.5 & 37.9 & $17 \cdot 4$ & 33.9 & $24 \cdot 1$ & 0.32 & 1.6 & 6.9 & $11 \cdot 0$ & 0.70 & 0.97 \\
\hline
\end{tabular}

* The categories correspond to rarely, $<1$ serving/week, 1-2 servings/week, 2-3 servings/week and 3 or more servings/week.

Women in the highest categories of seafood consumption had higher consumption of all seafood subtypes as well as higher intake of supplementary marine $n$ - 3 fatty acids (Table 2 ).

The average (mean) infant birth size measures were 3590 (SD 540)g for birth weight, $50 \cdot 36$ (SD 2.26) $\mathrm{cm}$ for birth length and $35.30(\mathrm{SD} 1.58) \mathrm{cm}$ for head circumference. In the unadjusted analysis, birth weight increased with increasing consumption of seafood (Fig. 2). The unadjusted $\beta$ coefficients for intake of total seafood and of lean fish were positive for all birth size measures, while supplementary $n$ - 3 was negatively associated with birth weight and head circumference (Table 3). When adjusting for confounders, the magnitude of the observed $\beta$ coefficients decreased for all items except shellfish. However, the significant positive associations between total seafood and lean fish and birth weight and head circumference remained. Likewise, the inverse association between supplementary $n-3$ and head circumference remained significant (Table 3 ). The covariates contributing most to attenuating the associations were parity and pregnancy duration, variables with strong independent influence on the infant birth measures.

Maternal weight gain in pregnancy, which was available for a subset of participants, was negatively associated with seafood consumption. Adjusting for gestational weight gain strengthened the association between intakes of seafood and lean fish regarding all birth measures (data not shown).

Examining seafood intake by categories of $20 \mathrm{~g} / \mathrm{d}$ increase showed that maternal seafood consumption had to be at least $20 \mathrm{~g} / \mathrm{d}$ (one serving weekly) to be significantly related to birth weight and head circumference (Table 3). Examining $n-3$ from fish-oil/cod-liver oil supplements by categories showed that the negative association with infant head circumference was evident in both the low $(<0.4 \mathrm{~g} / \mathrm{d})$ and the high $(\geq 0.4 \mathrm{~g} / \mathrm{d}$ ) intake category (Table 3 ).

Other dietary variables also influence infant birth size. We examined whether adjusting for intakes of meat, milk, coffee or vegetables attenuated the association between seafood and birth weight. Including these dietary variables in the models increased rather than attenuated the $\beta$-value for seafood intake (data not shown). We also examined the association between the total calculated intake of seafoodspecific nutrients (e.g. iodine and Se) and birth weight. From the results, it was not possible to attribute the observed influence of lean fish or total seafood to specific nutrients (data not shown).

Because the association between seafood consumption and birth weight may be modified by pregnancy duration, parity, smoking or age covariates, we also examined the association after stratifying by influential covariates. The positive association between maternal seafood intake and infant birth weight was consistent in all strata of pregnancy duration, parity, maternal age, height and BMI, maternal education and total energy intake. However, the strength of the association ( $\beta$-value) was lower in primparous than in multiparous women and among women with pregnancy duration $<37$ weeks compared with full-term pregnancies (data not shown).

On the basis of the positive association between maternal seafood consumption and birth weight, we examined the influence of seafood consumption on the risk of giving birth to small or large babies in full-term pregnancies (pregnancy duration $\geq 37$ completed weeks). In total, 437 (0.7\%) infants had birth weights $<2500 \mathrm{~g}$ and 2526 (4.3\%) had birth weights $>4500 \mathrm{~g}$. The relative risk of giving birth to a small baby decreased with increasing seafood intake, and was significantly lower in women who consumed $>60 \mathrm{~g} / \mathrm{d}$ of seafood than in women who consumed $\leq 5 \mathrm{~g} / \mathrm{d}$; adjusted $\mathrm{OR}=0.56$ (95\% CI $0.35,0.88)$. Neither total seafood nor lean fish consumption increased the risk of giving birth to a large baby (data not shown).

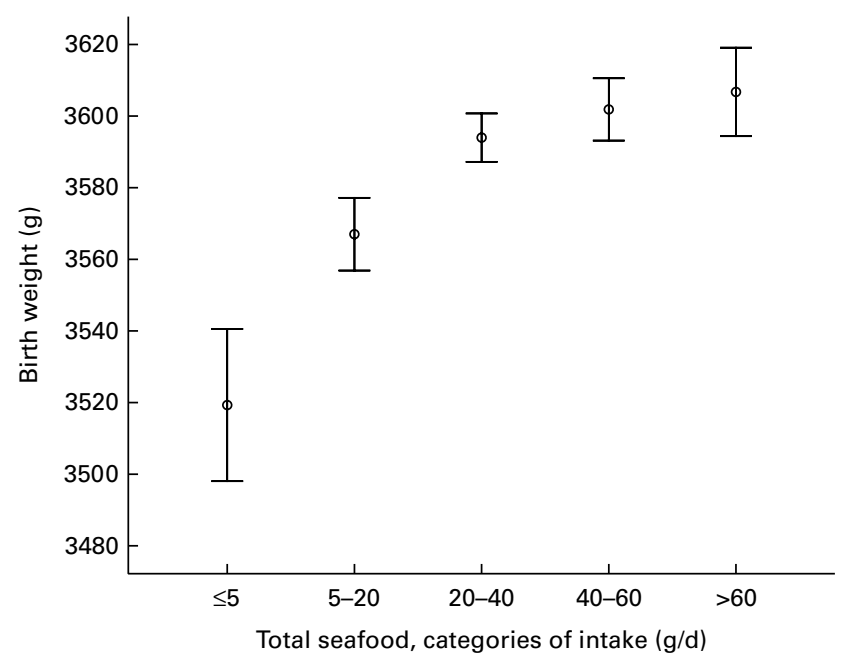

Fig. 2. Birth weight by categories of total seafood intake in 62099 women in the Norwegian Mother and Child Cohort Study. The values are means and $95 \% \mathrm{Cl}$. 
Table 3. Impact of seafood consumption on birth weight, birth length and head circumference of infants born to 62099 women* in the Norwegian Mother and Child Cohort Study, 2002-2008 ( $\beta$ Coefficients and $95 \%$ confidence intervals)

\begin{tabular}{|c|c|c|c|c|c|c|c|c|c|c|c|c|}
\hline & \multicolumn{4}{|c|}{ Birth weight (g) } & \multicolumn{4}{|c|}{ Birth length $(\mathrm{cm})$} & \multicolumn{4}{|c|}{ Head circumference $(\mathrm{cm})$} \\
\hline & \multicolumn{2}{|c|}{ Unadjusted } & \multicolumn{2}{|c|}{ Adjusted $\dagger$} & \multicolumn{2}{|c|}{ Unadjusted } & \multicolumn{2}{|c|}{ Adjusted $\dagger$} & \multicolumn{2}{|r|}{ Unadjusted } & \multicolumn{2}{|c|}{ Adjusted $†$} \\
\hline & $\beta$ & $95 \% \mathrm{Cl}$ & $\beta$ & $95 \% \mathrm{Cl}$ & $\beta$ & $95 \% \mathrm{Cl}$ & $\beta$ & $95 \% \mathrm{Cl}$ & $\beta$ & $95 \% \mathrm{Cl}$ & $\beta$ & $95 \% \mathrm{Cl}$ \\
\hline Total seafood $\neq(\mathrm{g} / \mathrm{d})$ & 0.66 & $0.47,0.85$ & 0.27 & $0.12,0.42$ & 0.002 & $0.001,0.003$ & 0.000 & $0.000,0.001$ & 0.002 & $0.001,0.002$ & 0.001 & $0.001,0.002$ \\
\hline Lean fish $(\mathrm{g} / \mathrm{d})$ & 1.23 & $0.92,1.55$ & 0.45 & $0.16,0.65$ & 0.003 & $0.002,0.004$ & 0.001 & $0.000,0.002$ & 0.002 & $0.001,0.003$ & 0.002 & $0.001,0.003$ \\
\hline Fatty fish $(\mathrm{g} / \mathrm{d})$ & 0.15 & $-0.16,0.46$ & 0.04 & $-0.22,0.26$ & 0.001 & $-0.001,0.002$ & 0.000 & $-0.001,0.001$ & 0.000 & $-0.001,0.001$ & 0.000 & $-0.001,0.001$ \\
\hline Shellfish $(g / d)$ & 0.51 & $-0.27,1.30$ & 0.72 & $0 \cdot 10,1 \cdot 30$ & 0.001 & $-0.002,0.005$ & 0.001 & $-0.001,0.004$ & 0.001 & $-0.001,0.003$ & 0.001 & $-0.001,0.003$ \\
\hline Fish liver (g/d) & -0.09 & $-6 \cdot 42,6 \cdot 24$ & -1.24 & $-6.06,3.58$ & -0.017 & $-0.043,0.010$ & -0.017 & $-0.039,0.004$ & -0.013 & $-0.031,0.006$ & -0.015 & $-0.031,0.001$ \\
\hline Supplementary n-3 (g/d) & -5.42 & $-10 \cdot 3,-0.52$ & 0.53 & $-3 \cdot 25,4 \cdot 31$ & -0.011 & $-0.030,0.010$ & -0.009 & $-0.026,0.007$ & -0.029 & $-0.043,-0.015$ & -0.017 & $-0.029,-0.004$ \\
\hline \multicolumn{13}{|l|}{ Total seafood in categories } \\
\hline$\leq 5 \mathrm{~g} / \mathrm{d}$ & \multicolumn{2}{|c|}{ Referent } & \multicolumn{2}{|c|}{ Referent } & \multicolumn{2}{|c|}{ Referent } & \multicolumn{2}{|c|}{ Referent } & \multicolumn{2}{|r|}{ Referent } & \multicolumn{2}{|r|}{ Referent } \\
\hline$>5-20 \mathrm{~g} / \mathrm{d}$ & 47.7 & $25 \cdot 0,70 \cdot 0$ & 11.7 & $-5 \cdot 61,29 \cdot 0$ & 0.154 & $0.059,0.249$ & -0.016 & $-0.092,0.059$ & 0.114 & $0.048,0.180$ & 0.043 & $-0.014,0.099$ \\
\hline$>20-40 \mathrm{~g} / \mathrm{d}$ & $74 \cdot 7$ & $53 \cdot 3,96 \cdot 1$ & 20.5 & $4.03,36.9$ & 0.269 & $0.179,0.359$ & 0.040 & $-0.032,0.112$ & 0.163 & $0.101,0.225$ & 0.055 & $0.002,0.109$ \\
\hline$>40-60 \mathrm{~g} / \mathrm{d}$ & $82 \cdot 6$ & $60 \cdot 4,105$ & $18 \cdot 6$ & $1 \cdot 53,35 \cdot 6$ & 0.285 & $0.192,0.378$ & 0.028 & $-0.046,0.102$ & 0.227 & $0.163,0.291$ & 0.099 & $0.043,0.155$ \\
\hline$>60 \mathrm{~g} / \mathrm{d}$ & 87.4 & $63 \cdot 7,111$ & $32 \cdot 2$ & $14 \cdot 0,50 \cdot 5$ & 0.249 & $0.149,0.348$ & 0.028 & $-0.052,0.108$ & 0.209 & $0.140,0.278$ & 0.102 & $0.042,0.162$ \\
\hline $\begin{array}{l}P \text { for trend } \\
\text { Supplementary } n-3(\mathrm{~g} / \mathrm{d})\end{array}$ & \multicolumn{2}{|r|}{$<0.001$} & \multicolumn{2}{|r|}{$<0.001$} & \multicolumn{2}{|c|}{$<0.001$} & \multicolumn{2}{|r|}{0.131} & \multicolumn{2}{|r|}{$<0.001$} & \multicolumn{2}{|r|}{$<0.001$} \\
\hline No & \multicolumn{2}{|c|}{ Referent } & \multicolumn{2}{|c|}{ Referent } & \multicolumn{2}{|c|}{ Referent } & \multicolumn{2}{|c|}{ Referent } & \multicolumn{2}{|r|}{ Referent } & \multicolumn{2}{|r|}{ Referent } \\
\hline$<0.39$ & $-27 \cdot 7$ & $-38 \cdot 3,-17 \cdot 1$ & -2.03 & $-10 \cdot 4,6 \cdot 29$ & -0.35 & $-0.80,0.009$ & -0.028 & $-0.064,0.008$ & -0.082 & $-0.114,-0.050$ & -0.036 & $-0.063,-0.009$ \\
\hline $0.40-6.9$ & $-22 \cdot 8$ & $-33 \cdot 4,-12 \cdot 2$ & 0.74 & $-7.60,9.07$ & -0.35 & $-0.79,0.009$ & -0.032 & $-0.069,0.004$ & -0.084 & $-0.116,-0.052$ & -0.043 & $-0.070,-0.015$ \\
\hline$P$ for trend & & $<0.001$ & & 0.835 & & 0.122 & & 0.086 & & $<0.001$ & & 0.002 \\
\hline
\end{tabular}

\section{${ }^{\star}$ For birth length $n 61387$ and for head circumference $n 60805$.}

† Adjusted for maternal age, height, pre-pregnant BMI, parity, pregnancy duration, maternal education, smoking status, mother tongue other than Norwegian and total energy intake, and with intakes of seafood/seafood items and

supplementary $n-3$ mutually adjusted.
$\ddagger$ Total seafood comprises lean fish (including fish in products), fatty fish, shellfish and fish liver. 


\section{Discussion}

The main finding in the present study was the positive association between infant birth weight and head circumference with increasing maternal seafood consumption. This association was mainly driven by the consumption of lean fish. Maternal intake of marine $n-3$ fatty acids through fish-oil/ cod-liver oil supplements was associated with a small but significantly smaller head circumference of the baby. Significantly reduced rates of low birth weight babies $(<2500 \mathrm{~g})$ were found in women who consumed more than $60 \mathrm{~g}$ of seafood/d as compared to women with no or very low intakes. The results of the present study did not show negative associations between maternal consumption of any fish or seafood items and infant birth weight, length or head circumference.

The finding of a positive association between maternal fish intake and increase in birth size in the present study is in concordance with other epidemiological studies that reported increased fetal growth measures with increasing fish intake $^{(7-10,17)}$. In seemingly contrast to these results, higher rates of birth weights below the 10th percentile were found in women who consumed more than $60 \mathrm{~g}$ of fish/d than in women with low fish intake in the Danish national birth cohort $^{(14)}$. However, the negative associations between fish intakes and fetal growth measures were only seen for consumption of fatty fish and not for consumption of lean fish. Similar results from a US cohort also found that marine $n-3$ fatty acid intake, or fish consumption, was associated with reduced fetal growth ${ }^{(16)}$. The present study results did not indicate any association between fatty fish and birth size, but a small negative influence was observed for supplementary $n-3$ in relation to infant head circumference. A significant negative association between intake of fish oil and infant head circumference was previously reported among pregnant women in Iceland ${ }^{(10)}$. Although the clinical importance of the small negative association between supplementary $n-3$ and head circumference in the present study is uncertain, this finding parallels the negative associations reported for fatty fish or fish oil in the other studies ${ }^{(10,14,16)}$

It has been suggested that differences observed regarding maternal seafood consumption and fetal growth might be indirect evidence of harmful contaminants in fish and can therefore reflect a true causal pattern ${ }^{(20)}$. Few studies have examined potential associations between exposure to persistent contaminants and birth size. A Spanish study that showed increased risk of small for gestational age with high intake of crustaceans and tuna adjusted the analysis for known contaminants in maternal blood (polychlorinated biphenyls and dichlorodiphenyldichloroethylene), but this did not change the results ${ }^{(19)}$. Lean fish is the primary source of dietary exposure to organic $\mathrm{Hg}$ and As. In a previous study in $\mathrm{MoBa}$ we showed that blood $\mathrm{Hg}$ concentrations were low ${ }^{(25)}$. Given the consistent positive association between lean fish consumption and birth weight in the present study there is no reason to believe that the relatively low dietary $\mathrm{Hg}$ exposure from lean fish consumed in Norway negatively influence infant birth weight.
When two opposing forces, beneficial nutrients important for fetal growth and harmful contaminants, coexist in the same food in varying amount/proportion, the results are bound to be different in different populations ${ }^{(20)}$. Large differences in terms of seafood and supplementary $n$ - 3 consumption exist between countries and even within the same country. Despite a decrease in fish intake over the past decades, a higher proportion of women in our study reported intakes $>60 \mathrm{~g} / \mathrm{d}(12.5 \%)$ than those in the Danish cohort $(5.6 \%)^{(14)}$. In addition to differences in patterns of consumption, the concentrations of nutrients and contaminants in various seafood items depend on whether these are farmed or wild $^{(21)}$, and for wild species also with origin and depth ${ }^{(22)}$. The concentration of organic pollutants in Norwegian farmed fish has been reduced over the last years and are now lower than that in wild fish ${ }^{(21)}$. Even the cooking method has been shown to influence the concentration of persistent organic pollutants in seafood ${ }^{(38,39)}$. The concentrations of organic pollutants in Norwegian commercial cod-liver oil/ fish-oil supplements have also been substantially reduced over the last decades, as improved methods to remove contaminants were introduced during the $1990 \mathrm{~s}^{(40)}$. However, not all contaminants are or can be fully removed ${ }^{(41,42)}$.

The main strength of this study is the large sample of pregnant Norwegian women. MoBa is a pregnancy cohort representing women with wide ranges of seafood intake, age, BMI, height and socioeconomic status. Seafood consumption was assessed with a detailed FFQ that was developed and validated for use in pregnancy ${ }^{(24)}$. A limitation of the present study is that the FFQ was answered in mid pregnancy and covered a time period that for many women has been biased by nausea and may not reflect the dietary intakes later in pregnancy. This may have influenced the reported dietary intakes and is likely to attenuate the observed associations. Furthermore, fish and seafood intakes, as well as $n-3$ supplement use, were higher in women of older age, nonsmokers and those with higher educational attainment (Table 1). We reduced the possibility of confounding by adjusting for a number of relevant factors. Adjusting for parity, maternal age, smoking, and other maternal factors markedly attenuated the associations between seafood consumption and birth size measures (Table 3). Still, the associations between seafood and lean fish remained consistent, but we cannot rule out the possibility that residual or unmeasured confounding may still exist. Many variables influence fetal growth. Gestational weight gain has a strong influence on birth weight ${ }^{(43)}$. Adjusting for gestational weight gain in a subset of our study population strengthened the positive association between seafood and lean fish on infant birth weight. This finding is in accordance with the results reported from Iceland ${ }^{(10)}$ and France ${ }^{(17)}$. We also examined whether other independent dietary variables biased the association between maternal seafood consumption and fetal growth. For comparison, meat intake contributed more to the total intake of protein and energy than seafood, but adjusting for meat, milk or other dietary factors did not attenuate the associations between seafood or lean fish and birth weight. This indicates that the observed associations between maternal 
seafood intakes and birth weight cannot easily be explained by the overall dietary behaviour in fish consumers.

In observational studies such as this, applying the Hill criteria for assessing disease causation can give further insight into the nature of the relation found ${ }^{(44)}$. The magnitude (strength criteria) of the association between seafood intake and birth weight was consistent in all strata of maternal characteristics. Information about seafood consumption preceded delivery (temporality criteria). A biological mechanism (plausibility criteria) underlying the positive association between seafood and birth weight is not obvious. In the present study, it was not possible to attribute the influence to specific nutrients or constituents. The health benefits of fish consumption documented in human studies (e.g. reduced risk of $\mathrm{CHD}$ mortality) are mostly related to consumption of species with a high content of $n-3$ fatty acids ${ }^{(45)}$. The associations between maternal seafood consumption and infant birth measures observed in the present study are unlikely to be explained by marine $n-3$ fatty acids because consumption of lean fish seemed to be the driving force of the association (Table 3). One possible explanation may be the composition of protein in fish. Bioactive peptides released from proteins upon intestinal digestion may modulate specific physiological functions in the human body ${ }^{(46)}$. We were not able to calculate concentrations of specific amino acids in this study, but experimental studies have shown that fish proteins fed to pregnant rodents have beneficially influenced insulin resistance and blood pressure in the offspring ${ }^{(47,48)}$. If the association stands true, and whether the increased birth weight is due to the special composition of fish proteins or other substances or a combination of these, remains to be seen.

In conclusion, this study indicated a consistent increase in infant birth weight and head circumference with increasing maternal seafood consumption and that this association was mainly driven by lean fish. Maternal intake of marine $n-3$ fatty acids through fish-oil/cod-liver oil supplements was associated with a small decrease in head circumference. These results corroborate the present dietary recommendation to pregnant Norwegian women, which is to include fish and seafood as part of a balanced diet, but to eliminate or avoid highly polluted items such as fish liver. The coexistence of persistent chemical pollutants and essential nutrients in natural foods such as seafood is a serious problem, and more studies are warranted to further disentangle the interplay between nutrients and contaminants in nutritional epidemiology.

\section{Acknowledgements}

The study was supported by the Norwegian Ministry of Health, NIH/NIEHS (grant no. N01-ES-85433), NIH/NINDS (grant no. 1 UO1 NS 047537-01), the 6th Research Framework of the European Union and the Norwegian Research Council/ FUGE (grant no. 151918/S10). The authors declare that they have no conflicts of interests. A. L. B. and B. E. B. conducted the statistical analyses and wrote the paper. M. H. was in charge of the coordination of the data file and analyses. H. M. M., H. E. K., J. A. and P. M. contributed to the interpretation of the results. All authors reviewed the paper.

\section{References}

1. Barker DJ (1990) The fetal and infant origins of adult disease. BMJ 301, 1111.

2. Whincup PH, Kaye SJ, Owen CG, et al. (2008) Birth weight and risk of type 2 diabetes: a systematic review. JAMA 300, 2886-2897.

3. Gunnarsdottir I, Birgisdottir BE, Thorsdottir I, et al. (2002) Size at birth and coronary artery disease in a population with high birth weight. Am J Clin Nutr 76, 1290-1294.

4. Godfrey K, Robinson S, Barker DJ, et al. (1996) Maternal nutrition in early and late pregnancy in relation to placental and fetal growth. BMJ 312, 410-414.

5. Mahaffey KR, Clickner RP \& Bodurow CC (2004) Blood organic mercury and dietary mercury intake: National Health and Nutrition Examination Survey, 1999 and 2000 Environ Health Perspect 112, 562-570.

6. EFSA (2005) Opinion of the scientific panel on contaminants in the food chain on a request from the European Parliament related to the safety assessment of wild and farmed fish. EFSA J 236, 1-118.

7. Olsen SF, Grandjean P, Weihe P, et al. (1993) Frequency of seafood intake in pregnancy as a determinant of birth weight: evidence for a dose dependent relationship. $J$ Epidemiol Community Health 47, 436-440.

8. Olsen SF \& Secher NJ (2002) Low consumption of seafood in early pregnancy as a risk factor for preterm delivery: prospective cohort study. BMJ 324, 447.

9. Rogers I, Emmett P, Ness A, et al. (2004) Maternal fish intake in late pregnancy and the frequency of low birth weight and intrauterine growth retardation in a cohort of British infants. J Epidemiol Community Health 58, 486-492.

10. Thorsdottir I, Birgisdottir BE, Halldorsdottir S, et al. (2004) Association of fish and fish liver oil intake in pregnancy with infant size at birth among women of normal weight before pregnancy in a fishing community. Am J Epidemiol 160, 460-465.

11. Muthayya S, Dwarkanath P, Thomas T, et al. (2009) The effect of fish and omega-3 LCPUFA intake on low birth weight in Indian pregnant women. Eur J Clin Nutr $\mathbf{6 3}$, 340-346.

12. Olsen SF, Hansen HS, Secher NJ, et al. (1995) Gestation length and birth weight in relation to intake of marine $n$-3 fatty acids. BrJ Nutr 73, 397-404.

13. Elias SL \& Innis SM (2001) Infant plasma trans, $n-6$, and $n-3$ fatty acids and conjugated linoleic acids are related to maternal plasma fatty acids, length of gestation, and birth weight and length. Am J Clin Nutr 73, 807-814.

14. Halldorsson TI, Meltzer HM, Thorsdottir I, et al. (2007) Is high consumption of fatty fish during pregnancy a risk factor for fetal growth retardation? A study of 44824 Danish pregnant women. Am J Epidemiol 166, 687-696.

15. Grandjean P, Bjerve KS, Weihe P, et al. (2001) Birth weight in a fishing community: significance of essential fatty acids and marine food contaminants. Int J Epidemiol 30, 1272-1278.

16. Oken E, Kleinman KP, Olsen SF, et al. (2004) Associations of seafood and elongated $n-3$ fatty acid intake with fetal growth and length of gestation: results from a US pregnancy cohort. Am J Epidemiol 160, 774-783.

17. Guldner L, Monfort C, Rouget F, et al. (2007) Maternal fish and shellfish intake and pregnancy outcomes: a prospective cohort study in Brittany, France. Environ Health 6, 33.

18. Ramon R, Ballester F, Aguinagalde X, et al. (2009) Fish consumption during pregnancy, prenatal mercury exposure, and anthropometric measures at birth in a prospective motherinfant cohort study in Spain. Am J Clin Nutr 90, 1047-1055. 
19. Mendez MA, Plana E, Guxens M, et al. (2010) Seafood consumption in pregnancy and infant size at birth: results from a prospective Spanish cohort. J Epidemiol Community Health 64, 216-222.

20. Lee DH \& Jacobs DR Jr (2010) Inconsistent epidemiological findings on fish consumption may be indirect evidence of harmful contaminants in fish. J Epidemiol Community Health 64, 190-192.

21. NIFES (2009) Annual Report: Monitoring Programs for Residues of Therapeutic Agents, Illegal Substances, Pollutants and Other Undesirables in Farmed Fish. Bergen: National Institute of Nutrition and Seafood Research (NIFES). http:// www.nifes.no/index.php?page_id=\&article_id=3442\&lang $\mathrm{id}=2$

22. Haug LS, Thomsen C, Brantsæter AL, et al. (2010) Diet and particularly seafood are major sources of perfluorinated compounds in humans. Environ Int 36, 772-778.

23. Johansson L \& Solvoll K (1999) Norkost 1997. Landsomfattende kostholdsundersøkelse blant menn og kvinner $i$ alderen 16 - 79 år (National Dietary Survey among Males and Females, 16-79 years). Publication No. 2, ed. Oslo: National Council on Nutrition and Physical Activity (in Norwegian)

24. Meltzer HM, Brantsæter AL, Ydersbond TA, et al. (2008) Methodological challenges when monitoring the diet of pregnant women in a large study: experiences from the Norwegian Mother and Child Cohort Study (MoBa). Matern Child Nutr 4, 14-27.

25. Brantsæter AL, Haugen M, Thomassen Y, et al. (2010) Exploration of biomarkers for total fish intake in pregnant Norwegian women. Public Health Nutr 13, 54-62.

26. Haugen M, Brantsæter AL, Alexander J, et al. (2008) Dietary supplements contribute substantially to the total nutrient intake in pregnant Norwegian women. Ann Nutr Metab 52, 272-280.

27. Magnus P, Irgens LM, Haug K, et al. (2006) Cohort profile: The Norwegian Mother and Child Cohort Study (MoBa). Int J Epidemiol 35, 1146-1150.

28. Nilsen RM, Vollset SE, Gjessing HK, et al. (2009) Selfselection and bias in a large prospective pregnancy cohort in Norway. Paediatr Perinat Epidemiol 23, 597-608.

29. Irgens LM (2000) The Medical Birth Registry of Norway. Epidemiological research and surveillance throughout 30 years. Acta Obstet Gynecol Scand 79, 435-439.

30. Lauritsen J (2005) FoodCalc (Online). Available at http:// www.ibt.ku.dk/jesper/foodcalc (accessed February 2006).

31. Norwegian Food Safety Authority, Norwegian Directorate of Health, Department of Nutrition - University of Oslo (2005) Matvaretabellen (The Norwegian Food Table, in Norwegian). Oslo. www.matportalen.no/Matvaretabellen

32. Brantsæter AL, Haugen M, Alexander J, et al. (2008) Validity of a new food frequency questionnaire for pregnant women in the Norwegian Mother and Child Cohort Study (MoBa). Matern Child Nutr 4, 28-43.
33. Brantssæter AL, Haugen M, Hagve TA, et al. (2007) Selfreported dietary supplement use is confirmed by biological markers in the Norwegian Mother and Child Cohort Study (MoBa). Ann Nutr Metab 51, 146-154.

34. Kvalem HE, Knutsen HK, Thomsen C, et al. (2009) Role of dietary patterns for dioxin and PCB exposure. Mol Nutr Food Res 53, 1438-1451.

35. Norwegian Scientific Committee for Food Safety ad hoc Group (2007) A comprehensive assessment of fish and other seafood in the Norwegian diet. Oslo: Norwegian Scientific Committee for Food Safety. http://www.vkm.no/ dav/d94dff429b.pdf

36. Wilcox AJ (2001) On the importance-and the unimportance-of birth weight. Int J Epidemiol 30, 1233-1241.

37. Zhang X, Decker A, Platt RW, et al. (2008) How big is too big? The perinatal consequences of fetal macrosomia. Am J Obstet Gynecol 198, 517e1-517e6.

38. Del GL, Tittlemier S, Diamond M, et al. (2008) Cooking decreases observed perfluorinated compound concentrations in fish. J Agric Food Chem 56, 7551-7559.

39. Sherer RA \& Price PS (1993) The effect of cooking processes on PCB levels in edible fish tissue. Qual Assur 2, 396-407.

40. Breivik H \& Thorstad O (2005) Removal of organic environmental pollutants from fish oil by short-path distillation. Lipid Technol 17, 55-58.

41. Bourdon JA, Bazinet TM, Arnason TT, et al. (2010) Polychlorinated biphenyls (PCBs) contamination and aryl hydrocarbon receptor (AhR) agonist activity of omega-3 polyunsaturated fatty acid supplements: implications for daily intake of dioxins and PCBs. Food Chem Toxicol $\mathbf{4 8}$, 3093-3097.

42. Jacobs MN, Santillo D, Johnston PA, et al. (1998) Organochlorine residues in fish oil dietary supplements: comparison with industrial grade oils. Chemosphere 37, 1709-1721.

43. Thorsdottir I, Torfadottir JE, Birgisdottir BE, et al. (2002) Weight gain in women of normal weight before pregnancy: complications in pregnancy or delivery and birth outcome. Obstet Gynecol 99, 799-806.

44. Hill $\mathrm{AB}$ (1965) The environment and disease: association or causation? Proc R Soc Med 58, 295-300.

45. Mozaffarian D \& Rimm EB (2006) Fish intake, contaminants, and human health: evaluating the risks and the benefits. JAMA 296, 1885-1899.

46. Erdmann K, Cheung BW \& Schroder H (2008) The possible roles of food-derived bioactive peptides in reducing the risk of cardiovascular disease. J Nutr Biochem 19, 643-654.

47. Yahia DA, Madani S, Prost E, et al. (2003) Tissue antioxidant status differs in spontaneously hypertensive rats fed fish protein or casein. J Nutr 133, 479-482.

48. Tremblay F, Lavigne C, Jacques H, et al. (2003) Dietary cod protein restores insulin-induced activation of phosphatidylinositol 3-kinase/Akt and GLUT4 translocation to the T-tubules in skeletal muscle of high-fat-fed obese rats. Diabetes 52, 29-37. 